\title{
Uncertainty propagation through correction methodology for the determination of rare earth elements by quadrupole based inductively coupled plasma mass spectrometry
}

\author{
Narendra M. Raut ${ }^{\mathrm{a}}$, Li-Shing Huang ${ }^{\mathrm{b}}$, King-Chuen Lin ${ }^{\mathrm{b}, *}$, Suresh K. Aggarwal ${ }^{\mathrm{a}, *}$ \\ a Fuel Chemistry Division, Bhabha Atomic Research Centre, Trombay, Mumbai 400085, India \\ ${ }^{\mathrm{b}}$ Department of Chemistry, National Taiwan University, and Institute of Atomic and Molecular Sciences, Academia Sinica, Taipei 106, Taiwan, ROC
}

Received 15 April 2004; received in revised form 18 August 2004; accepted 18 August 2004

Available online 7 December 2004

\begin{abstract}
Determination of rare earth elements by quadrupole based inductively coupled plasma mass spectrometry (ICP-QMS) shows several spectroscopic overlaps from $\mathrm{M}^{+}, \mathrm{MO}^{+}$and $\mathrm{MOH}^{+}$ions. Especially, the spectroscopic interferences are observed from the atomic and molecular species of lighter rare earth elements including Ba during the determination of Eu, Gd and Tb. Mathematical correction methods, knowing the at.\% abundances of different interfering isotopes, and the extent of formation of molecular species determined experimentally, have been used to account for various spectroscopic interferences. However, the uncertainty propagated through the mathematical correction limits its applicability. The uncertainty propagation increases with the increase in contribution from interfering species. However, for the same extent of total contribution, the overall error decreases when the interfering species are more than one. In this work, chondrite as well as a few geological reference materials containing different proportions of various rare earth elements have been used to study the contributions of different interfering species and the corresponding uncertainty in determining the concentrations of rare earth elements. A number of high abundant isotopes are proposed for determining the concentrations of various rare earth elements. The proposed isotopes are tested experimentally for determining the concentrations of different rare earth elements in two USGS reference materials AGV-1 and G-2. The interferences over those isotopes are corrected mathematically and the uncertainties propagated due to correction methodology are determined for those isotopes. The uncertainties in the determined concentrations of rare earth elements due to interference correction using the proposed isotopes are found to be comparable with those obtained by the commonly used isotopes for various rare earth elements.
\end{abstract}

(C) 2004 Elsevier B.V. All rights reserved.

Keywords: Rare earth elements; ICP-QMS; Ultrasonication; Uncertainty propagation

\section{Introduction}

Rare earth elements represent a group of elements from La to $\mathrm{Lu}$, which shows similar physical and chemical properties. They play an important role in various fields ranging from geology to electronics, which demand their determination from percentage level to ultra-trace level [1]. Increasing use of

\footnotetext{
* Corresponding authors. Fax: +9122 2550 5151/25519613

(S.K. Aggarwal)/+86 886223621483 (K.C. Lin).

E-mail addresses: kclin@ccms.ntu.edu.tw (K.-C. Lin), skaggr@magnum.barc.ernet.in (S.K. Aggarwal).
}

rare earth elements for different applications increases their release into the environment. As a consequence, determination of rare earth elements is also needed for environmental and biological science $[2,3]$.

High selectivity and sensitivity along with multi-elemental detection capability of quadrupole based inductively coupled plasma mass spectrometry (ICP-QMS) have made this technique as a useful analytical tool for ultra-trace determination of different elements including rare earths. Since the launch of the first commercial ICP-QMS system in 1984, a number of papers have appeared in literature on its use for multielemental determinations in different matrices. This tech- 
nique is particularly attractive for determination of rare earth elements especially in geological samples without any chemical separation or pre-concentration [4]. As a result, many reports have been published for the determination of rare earth elements in geological samples by ICP-QMS [5-11]. However, the mass spectra are plagued by spectroscopic interferences from various species, e.g. oxides and hydroxides, which poses serious problem for determination of middle and heavier rare earth elements by ICP-QMS, particularly when the concentration ratio of lighter rare earths to heavier rare earths is high. In addition, Ba is one of the most abundant elements in many samples and its oxides and hydroxides also interfere with determination of some of the rare earth elements, e.g. Eu.

Reduction of oxide and hydroxide formation in plasma has been the focus of research for many years. Several methods including desolvation techniques like ultrasonic nebuliser [12], membrane dryer [13] and cryogenic desolvation [8] have been adopted to reduce the metal oxide formation in the ICP torch. Other attempts such as changes in plasma gas composition [14,15], changes in sampler and skimmer orifice size [16], optimization of the distance between them [17], and changes in sampling depth [13] have also been demonstrated to reduce the oxide formation. The dynamic reaction cell has also been introduced in the commercial ICP-QMS instruments, which makes use of collision/reaction with a gas to reduce the level of oxides present in the ion beam $[18,19]$.

In spite of reduction in the formation of oxide and hydroxide species, mathematical correction methodology has to be adopted to account for the oxide and hydroxide overlap problem [20,21]. Vaughan and Horlick compared the use of multiple component analysis method with Gauss elimination for rare earth elements determination by ICP-QMS [22]. Dulski reported a degree of interference during rare earth elements determination by ICP-QMS under the routine conditions [7]. However, these publications do not allow the estimation of uncertainties due to interference correction in the corrected rare earth elements signals. As is obvious, due to large corrections required, coupled with increased uncertainty in the correction, this method has not been preferred for determination of lighter rare earth elements specifically $\mathrm{Eu}$ in presence of relatively high concentrations of Ba. Jarvis used doubly charged Eu ions for its determination to circumvent the spectroscopic interferences from oxide and hydroxide species of $\mathrm{Ba}$ [23]. Unusual severe loss of sensitivity limited the use of doubly charged ions in Eu determination at ultra-trace level. Cao et al. used chromatographic separation for Ba to avoid large mathematical correction at Eu [24]. Though the separation is required only in very unusual and exceptional samples, yet the procedure is tedious and time consuming.

The speed as well as ease of application of mathematical correction methodology without any additional experimental step motivated us to study in detail, the advantages and drawbacks of this approach. This was done by estimating the contributions from various interfering species using experimental data on the formation of oxides and hydroxides and the corresponding uncertainty associated with them for the determination of rare earth elements by ICP-QMS.

A discussion of the best choice of isotopes on the basis of degree of oxide formation of potential interfering elements to be used for rare earth elements analysis was reported by Longerich et al. [25]. However, some of the high abundant isotopes of rare earth elements showing relatively more but correctable interferences have not been considered in those discussions. In this work, four different geological reference materials, chondrite and a synthetic mixture were used to identify the most suitable isotopes for determination of different rare earth elements. It is demonstrated that in many cases, more than one isotope can be used for determining the rare earth element concentrations by ICP-QMS, without worrying about the number of interfering species. Though, conventionally one isotope has been preferred due to more interferences on the other isotopes, however, the use of more than one isotope enhances the confidence in the concentration values obtained using ICP-QMS. It also helps in identifying isotopic anomalies, if any, in case of non-natural isotopic composition of the element, e.g. in natural reactor popularly known as OKLO phenomenon or in case of samples from a nuclear reactor or irradiation experiments.

\section{Experimental}

\subsection{Apparatus}

A SCIEX ELAN 6000 ICP-QMS (Perkin-Elmer, USA), with cross flow nebuliser described elsewhere [26], was used for analyzing various samples. The sampling depth between the sampler tip and top coil was fixed at $9 \mathrm{~mm}$ for all data acquisition. The coolant gas flow rate and the auxiliary gas flow rate were fixed at 15.0 and $1.0 \mathrm{~L} / \mathrm{min}$. The aerosol gas flow rate and the r.f. power were optimized daily using $10 \mathrm{ppb} \mathrm{Ce}$ solution to optimize the sensitivity along with fraction oxide formation. The typical values were $0.95 \mathrm{~L} / \mathrm{min}$ for aerosol gas flow and $1250 \mathrm{~W}$ as the r.f. power.

\subsection{Reagents}

De-ionized water (Millipore, USA) was used for the preparation of solutions. Indium (1000 ppmw) was procured from Merck. All the rare earth elements solutions $10 \mathrm{ppmw}$ each and $\mathrm{Ba}(1000 \mathrm{ppmw})$ standard solution were purchased from High-Purity Standards, USA and diluted to desired concentrations by $1 \% \mathrm{HNO}_{3}$. Rock samples AGV-1 and G-2 with recommended values for rare earth elements and $\mathrm{Ba}$ were obtained from the United States Geological Survey. Trace pure grade $\mathrm{HNO}_{3}$ and supra pure grade $\mathrm{HF}$ obtained from Merck were used for digestion and dissolution of rock samples. Finally, all the solutions and samples were prepared in $1 \% \mathrm{HNO}_{3}$ for ICP-QMS analysis. 


\subsection{Rock sample preparation}

Ultrasonication [27] in conc. $\mathrm{HF}$ and conc. $\mathrm{HNO}_{3}$ medium was employed for the extraction of rare earth elements from solid silicate matrices. An amount of $25 \mathrm{mg}$ of AGV-1 was dissolved in PTFE beaker using a mixture of $0.5 \mathrm{~mL}$ conc. $\mathrm{HF}$ and $5 \mathrm{~mL}$ conc. $\mathrm{HNO}_{3}$, by heating on a hot plate followed by ultrasonication, for $1.5-2 \mathrm{~h}$. To extract the ultratrace heavier rare earth elements in G-2, the above digestion medium was modified to $1: 1 \mathrm{HCl}-\mathrm{HNO}_{3}$ in place of $\mathrm{HNO}_{3}$. The ultrasonication extraction time was also increased from 2 to $5 \mathrm{~h}$. The dissolved solutions showed no residue after the ultrasonic extraction. It may be added that undissolved minerals, if left, during the dissolution procedure are most likely zircons containing heavier rare earths and hence it was essential to carry out quantitative dissolution. The dissolved solutions were evaporated to dryness to remove the excess of fluorides and chlorides from $\mathrm{HF}$ and $\mathrm{HCl}$, respectively. They were further treated 2-3 times with conc. $\mathrm{HNO}_{3}$ to evaporate till dryness, followed by their dilution to the desired volume with $1 \% \mathrm{HNO}_{3}$ for ICP-QMS analysis.

\section{Mathematical correction method}

\subsection{Correction for polyatomic (oxide or hydroxide) isobaric species}

The correction methodology depends on the measurement of oxide and hydroxide yields of the interfering rare earth elements and $\mathrm{Ba}$, under the experimental conditions employed. The contribution due to these oxide/hydroxide species should be eliminated from the observed intensity of rare earth element to get corrected intensity. The estimation of this contribution can be explained with the help of an example as follows.

Let us take the example of Sm determination using ${ }^{147} \mathrm{Sm}$ and the isobaric interference of ${ }^{130} \mathrm{BaOH}$ at ${ }^{147} \mathrm{Sm}$. Since ${ }^{138} \mathrm{Ba}$ has no isobaric interference, has high abundance and can be monitored without any problem, the contribution $\left(I_{\mathrm{C}(\mathrm{BaOH})}\right)$ from ${ }^{130} \mathrm{BaOH}$ at ${ }^{147} \mathrm{Sm}$ in the sample can be calculated as follows

$$
\begin{aligned}
& \left(\frac{I_{130} \mathrm{BaOH}}{I_{130} \mathrm{Ba}}\right)_{\text {sample }}=\left(\frac{I_{138} \mathrm{BaOH}}{I_{138} \mathrm{Ba}}\right)_{\text {sample }} \text { or } \\
& I_{130 \mathrm{BaOH}(\text { sample })}=\frac{I^{138} \mathrm{BaOH}(\text { sample })}{I_{138} \mathrm{Ba}(\text { sample })} I_{130} \mathrm{Ba} \text { (sample) } \text { or } \\
& I_{130} \mathrm{BaOH}(\text { sample })= \\
& =\frac{I^{138} \mathrm{BaOH}(\text { sample })}{{ }^{138} \mathrm{Ba}(\text { at. } \%)}{ }^{130} \mathrm{Ba}(\text { at. } \%) K
\end{aligned}
$$

where $K$ is the mass discrimination factor of the instrument under those experimental conditions and is defined as $K=$ $\left[I_{130} \mathrm{Ba} / I_{138} \mathrm{Ba}\right]_{\text {sample }} /\left[{ }^{130} \mathrm{Ba}(\text { at. } \%) /{ }^{138} \mathrm{Ba}(\text { at. } \%)\right]_{\text {IUPAC }}$.
Assuming $\left(I_{138} \mathrm{BaOH} / I_{138} \mathrm{Ba}\right)_{\text {sample }}=\left(I_{138} \mathrm{BaOH} /\right.$

$\left.I_{138} \mathrm{Ba}\right)_{\text {standard }}$

$I_{138} \mathrm{BaOH}($ sample $)=\left(\frac{I_{138} \mathrm{BaOH}}{I_{138} \mathrm{Ba}}\right)_{\text {standard }} I_{138} \mathrm{Ba}($ sample $)$

Substituting Eq. (2) into Eq. (1)

${ }^{I}{ }_{130} \mathrm{BaOH}$ (sample)

$$
=\left(\frac{I_{138} \mathrm{BaOH}}{I_{138} \mathrm{Ba}}\right)_{\text {standard }} I_{138} \mathrm{Ba}(\text { sample }) \frac{{ }^{130} \mathrm{Ba}(\text { at. } \%)}{{ }^{138} \mathrm{Ba}(\text { at. } \%)} K \quad \text { or }
$$

${ }^{130} \mathrm{BaOH}($ sample $)=\left(Y_{\mathrm{BaOH}}\right) I_{138} \mathrm{Ba}($ sample $) \frac{{ }^{130} \mathrm{Ba}(\text { at. } \%)}{{ }^{138} \mathrm{Ba}(\text { at. } \%)} K$

where, $Y_{\mathrm{BaOH}}=\left(I_{138} \mathrm{BaOH} / I_{138} \mathrm{Ba}\right)$ denotes the yield of $\mathrm{BaOH}^{+}$and $I_{138} \mathrm{Ba}$ (sample) is the intensity of ${ }^{138} \mathrm{Ba}$ in the sample. If $I_{147} \mathrm{Sm}$ (sample) is the observed intensity of ${ }^{147} \mathrm{Sm}$ in the sample, then the corrected intensity $I_{147}^{\prime} \mathrm{Sm}$ (sample) of ${ }^{147} \mathrm{Sm}$ used for its determination in the sample will be

$I_{147}^{\prime} \mathrm{Sm}$ (sample) $=I_{147} \mathrm{Sm}$ (sample) $-I_{130} \mathrm{BaOH}($ sample $)$

In generalized form, the Eqs. (3) and (4) can be written as:

$I_{\mathrm{C}}=Y I_{\mathrm{B}(\text { sample })} \frac{b}{b^{\prime}} K$

$I_{\mathrm{A} \text { (sample) }}^{\prime}=I_{\mathrm{A} \text { (sample) }}-I_{\mathrm{C}}$

where $\mathrm{A}$ is the isotope for the analyte of interest to be determined, B the isotope (used as a monitor) of interfering element, $b$ and $b^{\prime}$ are the IUPAC recommended at.\%'s of interfering isotope and monitored isotope of interfering element, $I_{\mathrm{B} \text { (sample) }}$ the intensity of interfering element, $I_{\mathrm{C}}$ the contribu-

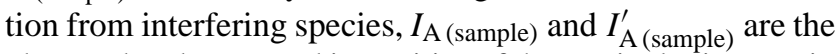
observed and corrected intensities of the particular isotope in the sample. The methodology is based on the yield $(Y)$ determined using the major abundant isotope of the interfering element and hence would allow more accurate interference correction.

\subsection{Correction for atomic isobaric species}

For atomic isobaric species $Y=1$, hence, Eq. (5) becomes

$I_{\mathrm{C}}=I_{\mathrm{B}(\text { sample })} \frac{b}{b^{\prime}} K$

\subsection{Correction for multiple isobaric species}

When the analyte isotope has interference from more than one interfering species, the net contribution $\left(I_{\mathrm{C}}\right)$ from different species can be calculated as

$I_{\mathrm{C}}=I_{\mathrm{C} 1}+I_{\mathrm{C} 2}+\cdots+I_{\mathrm{C} n}$

where, $I_{\mathrm{C} 1}, I_{\mathrm{C} 2}, \ldots, I_{\mathrm{C} n}$ the contributions from different interfering species $1,2, \ldots, n$, respectively, can be obtained as 
follows

$I_{\mathrm{C} 1}=Y_{1} I_{\mathrm{B} 1(\text { sample })} \frac{b_{1}}{b_{1}^{\prime}} K_{1}$

$I_{\mathrm{C} 2}=Y_{2} I_{\mathrm{B} 2(\text { sample })} \frac{b_{2}}{b_{2}^{\prime}} K_{2}$

$I_{\mathrm{C} n}=Y_{n} I_{\mathrm{B} n(\text { sample })} \frac{b_{n}}{b_{n}^{\prime}} K_{n}$

followed by Eq. (6)

\subsection{Corrected concentration of analyte in sample}

From the corrected intensity of analyte in sample ( $\left.I_{\mathrm{A} \text { (sample) }}^{\prime}\right)$ obtained by Eq. (6) and the intensity of analyte in its standard solution $\left(I_{\mathrm{A} \text { (standard) }}\right)$, the correct concentration of analyte [A] in the sample using a appropriate dilution factor $(D)$ can be obtained as follows

$[\mathrm{A}]=\frac{I_{\mathrm{A}(\text { sample })}^{\prime}}{I_{\mathrm{A}(\text { standard })}} D$

\section{Propagation of measurement uncertainties}

\subsection{For polyatomic (oxide or hydroxide) isobaric species}

ICP-QMS determination of rare earth elements involves several experimental measurements, which are subjected to indeterminate uncertainties, which finally contribute to net indeterminate error in the final result. For instance, Eq. (5) in combination with Eq. (6) used for oxide or hydroxide correction is considered for error propagation. The uncertainties in the variables in Eq. (5) propagate in the final corrected intensity. The uncertainty propagation through Eq. (5) can be calculated as follows

$\sigma_{I_{\mathrm{C}}}=I_{\mathrm{C}} \sqrt{\begin{array}{c}\left(\frac{\sigma_{Y}}{Y}\right)^{2}+\left(\frac{\sigma_{I_{\mathrm{B} \text { (sample })}}}{I_{\mathrm{B} \text { (sample })}}\right)^{2}+\left(\frac{\sigma_{b}}{b}\right)^{2} \\ +\left(\frac{\sigma_{b^{\prime}}}{b^{\prime}}\right)^{2}+\left(\frac{\sigma_{K}}{K}\right)^{2}\end{array}}$

\subsection{For atomic isobaric species}

For atomic isobaric interference correction as $Y=1$, Eq. (10) will change as follows

$\sigma_{I_{\mathrm{C}}}=I_{\mathrm{C}} \sqrt{\left(\frac{\sigma_{I_{\mathrm{B} \text { (sample })}}}{I_{\mathrm{B} \text { (sample) }}}\right)^{2}+\left(\frac{\sigma_{b}}{b}\right)^{2}+\left(\frac{\sigma_{b^{\prime}}}{b^{\prime}}\right)^{2}+\left(\frac{\sigma_{K}}{K}\right)^{2}}$

\subsection{For multiple isobaric species}

When the contribution is from more than one interfering species as shown in Eq. (8), the propagated uncertainty in the net contribution $\left(\sigma_{I_{\mathrm{C}}}\right)$ can be calculated as follows

$\sigma_{I_{\mathrm{C}}}=\sqrt{\left(\sigma_{I_{\mathrm{C} 1}}\right)^{2}+\left(\sigma_{I_{\mathrm{C} 2}}\right)^{2}+\cdots+\left(\sigma_{I_{\mathrm{C} n}}\right)^{2}}$

\subsection{For corrected measured intensity of analyte}

If $\sigma_{I_{\mathrm{C}}}$ and $\sigma_{I_{\mathrm{A} \text { (sample) }}}$ are the uncertainties in the estimated contribution $\left(I_{\mathrm{C}}\right)$ and in the observed intensity of analyte $\left[I_{\mathrm{A} \text { (sample) }}\right]$, then, the final uncertainty $\left(\sigma_{I_{\mathrm{A} \text { (sample) }}^{\prime}}\right)$ in the corrected intensity $\left[I_{\mathrm{A}(\text { sample) }}^{\prime}\right]$ propagated through Eq. (6) will be

$\sigma_{I_{\mathrm{A}(\text { sample })}^{\prime}}=\sqrt{\left(\sigma_{\left.I_{\mathrm{A}(\text { sample })}\right)^{2}+\left(\sigma_{I_{\mathrm{C}}}\right)^{2}}\right.}$

\subsection{For corrected concentration of analyte in the sample}

The uncertainty propagated through Eq. (9) can be net uncertainty obtained in the determination of analyte in the given sample. This can be obtained using the following equation

$\sigma_{[\mathrm{A}]}=[\mathrm{A}] \sqrt{\left(\frac{\sigma_{I_{\mathrm{A}(\text { sample })}^{\prime}}}{I_{\mathrm{A} \text { (sample) }}^{\prime}}\right)^{2}+\left(\frac{\sigma_{I_{\mathrm{A}(\text { standard })}}}{I_{\mathrm{A} \text { (standard })}}\right)^{2}}$

\section{Results and discussion}

Spectroscopic interferences due to oxides and hydroxides formed from the analyte itself, the matrix component, the solvent and the plasma gases during ICP-MS are well recognized. Almost all the elements form $\mathrm{MO}^{+}$and $\mathrm{MOH}^{+}$ions to some extent. However, rare earth elements form the strongest oxide and hydroxide ions in ICP-QMS [28]. Moreover, the yields of oxides and hydroxides of lighter rare earth elements are much higher than those for heavier rare earth elements. These species occur at 16 and 17 amu above the parent ion and present a potential analytical problem for determination of low abundant heavier rare earth elements. In addition, the seven naturally occurring isotopes of $\mathrm{Ba}$ occur adjacent to the lighter rare earth elements, forming oxides and hydroxides. The oxide and hydroxide species of $\mathrm{Ba}$ are potential source of interference on the isotopes of middle rare earth elements, especially Eu. Both the isotopes of $\mathrm{Eu}\left({ }^{151} \mathrm{Eu}\right.$ and ${ }^{153} \mathrm{Eu}$ ), suffer serious overlaps from oxides and hydroxides of $\mathrm{Ba}$ isotopes, particularly when $\mathrm{Ba}: \mathrm{Eu}$ concentration ratio is greater than 200:1.

The correction methodology based on single element oxide measurement can be used to correct for these interferences. To achieve high sensitivity and good precision for the determination of any element, isotopes having high natural abundance should be selected. The interferences at the high abundant isotopes can be corrected using correction method- 

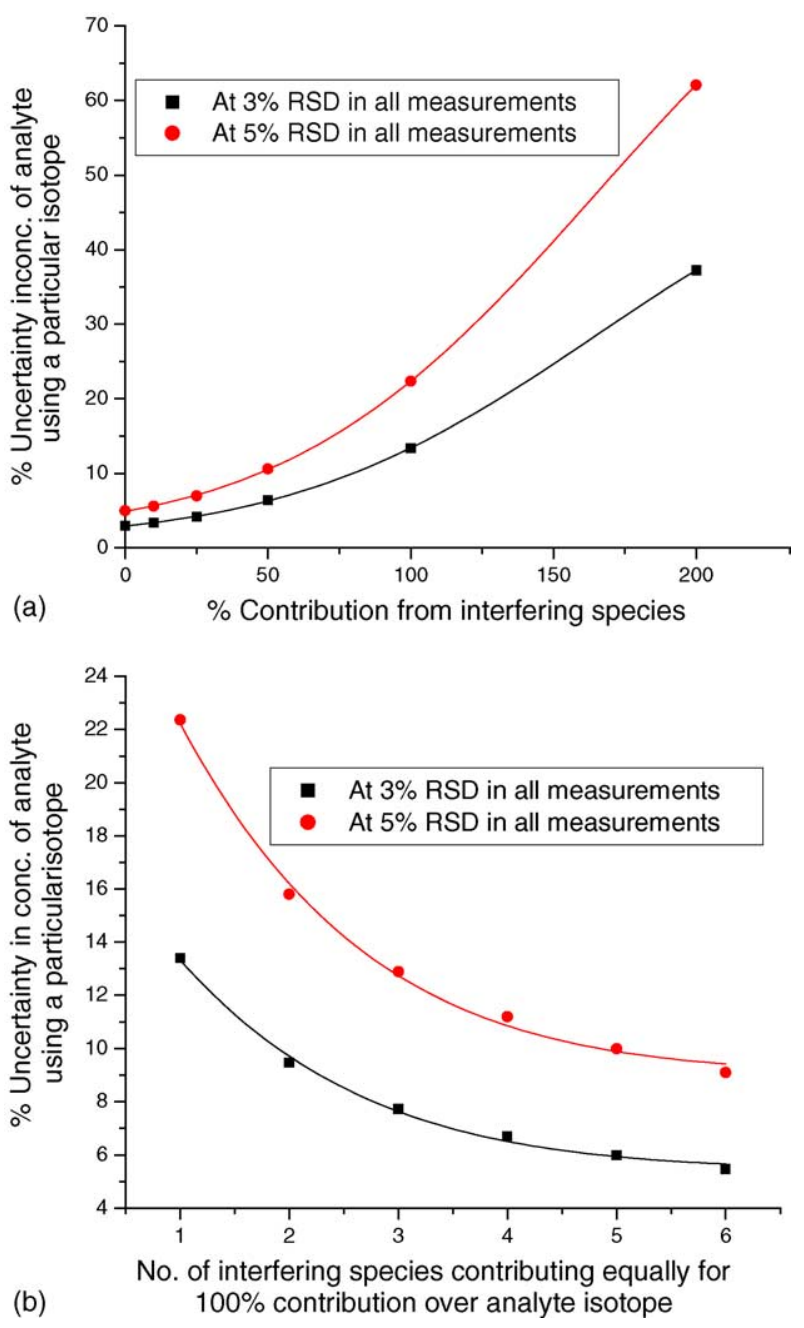

Fig. 1. Dependence of uncertainty propagation on (a) contribution from interfering species, as that of single species (b) number of contributing interfering species for the same total contribution divided equally among various species.

ology, however, the uncertainty propagated through the correction method would decide their suitability. The uncertainty due to correction depends on (a) the precision of analytical measurements, (b) the magnitude of contribution to be corrected, (c) the type of interfering species and (d) the number of contributing species. Fig. 1a and b show the dependence of uncertainty propagated on the $\%$ contribution of interfering species and the number of interfering species. As is obvious, for a fixed R.S.D. in analytical measurements, the uncertainty in the corrected signal of an isotope increases with increase in the contribution from interfering species. As shown in Fig. 1a, there is an exponential increase in uncertainty in corrected concentration of analyte using a particular isotope with increase in contribution from interfering species. This exponential increase is also dependent upon relative standard deviation of measurement, e.g. 5\% R.S.D. versus 3\% R.S.D. However, for the same extent of total \% contribution, the overall uncertainty decreases with the increase in number of contributing species as shown in Fig. 1b. As can be seen,
Table 1

Certified (recommended/provisional) concentrations in ppmw of rare earth elements in geological standards and in chondrite

\begin{tabular}{|c|c|c|c|c|c|}
\hline $\begin{array}{l}\text { Rare earth } \\
\text { element }\end{array}$ & $A C-E^{a}$ & $\mathrm{AGV}-1^{\mathrm{b}}$ & $\mathrm{G}-2^{\mathrm{b}}$ & GSP- $1^{b}$ & Chondrite $^{c}$ \\
\hline $\mathrm{La}$ & 59 & 38 & 89 & 184 & 0.235 \\
\hline $\mathrm{Ce}$ & 155 & 67 & 160 & 399 & 0.603 \\
\hline $\operatorname{Pr}$ & 22.2 & 7.6 & 18 & 52 & 0.089 \\
\hline $\mathrm{Nd}$ & 92 & 33 & 55 & 196 & 0.452 \\
\hline $\mathrm{Sm}$ & 24.2 & 5.9 & 7.2 & 26.3 & 0.147 \\
\hline $\mathrm{Eu}$ & 2.0 & 1.6 & 1.4 & 2.33 & 0.056 \\
\hline $\mathrm{Gd}$ & 26 & 5 & 4.3 & 12.1 & 0.197 \\
\hline $\mathrm{Tb}$ & 4.8 & 0.7 & 0.48 & 1.34 & 0.036 \\
\hline Dy & 29 & 3.6 & 2.4 & 5.5 & 0.243 \\
\hline Ho & 6.5 & 0.67 & 0.4 & 1.01 & 0.056 \\
\hline $\mathrm{Er}$ & 17.7 & 1.7 & 0.92 & 2.7 & 0.159 \\
\hline $\mathrm{Tm}$ & 2.6 & 0.34 & 0.18 & 0.38 & 0.024 \\
\hline $\mathrm{Yb}$ & 17.4 & 1.72 & 0.8 & 1.7 & 0.163 \\
\hline $\mathrm{Lu}$ & 2.45 & 0.27 & 0.11 & 0.21 & 0.024 \\
\hline $\mathrm{Ba}^{\mathrm{d}}$ & 55 & 1230 & 1880 & 1310 & 2.3 \\
\hline $\mathrm{Hf}^{\mathrm{d}}$ & 28.7 & 5.1 & 7.9 & 15.5 & 0.12 \\
\hline
\end{tabular}

${ }^{a}$ Refers to GIT-IWG geological standard (Ref. [31]).

${ }^{b}$ Refers to USGS geological standards (Ref. [32]).

${ }^{\mathrm{c}}$ Refers to chondrite often used for normalization of rare earth elements contents in geological standards (Ref. [33]).

${ }^{\mathrm{d}}$ Refers to spectroscopically interfering elements during determination of rare earth elements by ICP-QMS.

the uncertainty of $22.4 \%$ in the corrected concentration of analyte, assuming $100 \%$ contribution from single species at $5 \%$ R.S.D. in all analytical measurements decreases to $11.2 \%$ when the same contribution is from four equally contributing interfering species. Normally, the uncertainty would lie within $11.2-22.4 \%$, as all the four interfering species would never contribute equally. However, this suggests that for a particular isotope, even if the contributing species are more, it can be selected for determining the concentration of a rare earth element using correction methodology.

In this work, the uncertainty due to the interference correction is used as a parameter for proper choice of rare earth element isotope with maximum isotopic abundance. Table 1 gives the recommended concentration values of different reference materials used in the present work for experimental and/or calculation purposes. Table 2 a shows all rare earth elements isotopes in the mass range of 138-176, their natural abundances and the possible isobaric interferences from atomic, oxide or hydroxide species of rare earth elements, $\mathrm{Hf}$ and $\mathrm{Ba}$, theoretically calculated. Table $2 \mathrm{~b}$ shows the data on other interfering elements viz. Ba and Hf, for their different isotopes with natural abundances. The isotopes suggested by Longerich et al. and normally used by different researchers for determination of various rare earth elements are given in bold in Table $2 \mathrm{a}$. It can be seen that the major isotopes of $\mathrm{La}$ and $\mathrm{Ce}$ are free from isobaric interferences along with $\mathrm{Pr}$, which is mono-isotopic. However, the interferences on high abundant isotopes of rare earth elements occur from $\mathrm{Nd}$ to $\mathrm{Yb} .{ }^{144} \mathrm{Nd},{ }^{152} \mathrm{Sm},{ }^{160} \mathrm{Gd},{ }^{164} \mathrm{Dy},{ }^{166} \mathrm{Er}$ and ${ }^{174} \mathrm{Yb}$ are the isotopes of the high natural abundance of these rare earth elements. Comparative evaluation of contribution from 
Table 2

(a) Spectroscopic interferences and the corresponding uncertainties due to their corrections during the determination of rare earth elements by ICP-QMS

\begin{tabular}{|c|c|c|c|c|c|c|c|c|c|c|c|c|c|c|c|}
\hline \multirow[t]{2}{*}{$\overline{\mathrm{RE}}$} & \multirow[t]{2}{*}{ Mass } & \multirow[t]{2}{*}{ At. $\%$} & \multirow[t]{2}{*}{ Interference } & \multicolumn{2}{|l|}{ Synthetic mixture $^{\mathrm{a}}$} & \multicolumn{2}{|l|}{ AC-E } & \multicolumn{2}{|l|}{ AGV-1 } & \multicolumn{2}{|l|}{ G-2 } & \multicolumn{2}{|l|}{ GSP-1 } & \multicolumn{2}{|l|}{ Chondrite } \\
\hline & & & & $\%$ Contribution $^{\mathrm{b}}$ & $\%$ Uncertainty $^{\mathrm{b}}$ & $\%$ Contribution $^{\mathrm{b}}$ & $\%$ Uncertainty $\mathrm{y}^{\mathrm{b}}$ & $\%$ Contribution $^{\mathrm{b}}$ & $\%$ Uncertainty $\mathrm{y}^{\mathrm{b}}$ & $\%$ Contribution $^{\mathrm{b}}$ & $\%$ Uncertainty $^{\mathrm{b}}$ & $\%$ Contribution $^{\mathrm{b}}$ & \% Uncertainty ${ }^{\mathrm{b}}$ & $\%$ Contribution $^{\mathrm{b}}$ & $\%$ Uncertainty $^{\mathrm{b}}$ \\
\hline \multirow[t]{2}{*}{$\mathrm{La}$} & 138 & $0.090(1)$ & ${ }^{138} \mathrm{Ce},{ }^{138} \mathrm{Ba}$ & * & - & * & - & * & - & * & - & * & - & $*$ & - \\
\hline & 139 & $99.910(1)$ & - & 0 & 3.0 & 0 & 3.0 & 0 & 3.0 & 0 & 3.0 & 0 & 3.0 & 0 & 3.0 \\
\hline \multirow[t]{4}{*}{$\mathrm{Ce}$} & 136 & 0.185 (2) & ${ }^{136} \mathrm{Ba}$ & * & - & * & - & * & - & * & - & * & - & * & - \\
\hline & 138 & $0.251(2)$ & ${ }^{142} \mathrm{Nd},{ }^{138} \mathrm{Ba}$ & * & - & $*$ & - & * & - & * & - & * & - & * & - \\
\hline & 140 & $88.450(51)$ & - & 0 & 3.0 & 0 & 3.0 & 0 & 3.0 & 0 & 3.0 & 0 & 3.0 & 0 & 3.0 \\
\hline & 142 & $11.114(51)$ & ${ }^{142} \mathrm{Nd}$ & * & - & $*$ & - & * & - & * & - & * & - & * & - \\
\hline $\operatorname{Pr}$ & 141 & 100 & - & 0 & 3.0 & 0 & 3.0 & 0 & 3.0 & 0 & 3.0 & 0 & 3.0 & 0 & 3.0 \\
\hline \multirow[t]{7}{*}{$\mathrm{Nd}$} & 142 & $27.2(5)$ & ${ }^{142} \mathrm{Ce}$ & 42 & 5.5 & 70 & 8.8 & 84 & 11 & * & - & 85 & 11 & 55 & 6.9 \\
\hline & 143 & $12.2(2)$ & - & 0 & 3.0 & 0 & 3.0 & 0 & 3.0 & 0 & 3.0 & 0 & 3.0 & 0 & 3.0 \\
\hline & 144 & $23.8(3)$ & ${ }^{144} \mathrm{Sm}$ & 13 & 3.5 & 3.4 & 3.1 & 2.3 & 3.1 & 1.7 & 3.1 & 1.7 & 3.1 & 4.2 & 3.1 \\
\hline & 145 & $8.3(1)$ & - & 0 & 3.0 & 0 & 3.0 & 0 & 3.0 & 0 & 3.0 & 0 & 3.0 & 0 & 3.0 \\
\hline & 146 & $17.2(3)$ & ${ }^{130} \mathrm{BaO}$ & 0.0006 & 3.0 & 0.0004 & 3.0 & 0.02 & 3.0 & 0.02 & 3.0 & 0.004 & 3.0 & 0.003 & 3.0 \\
\hline & 148 & $5.7(1)$ & ${ }^{148} \mathrm{Sm},{ }^{132} \mathrm{BaO}$ & $*$ & - & 50 & 6.3 & 34 & 4.9 & 25 & 4.2 & 26 & 4.2 & 62 & 7.8 \\
\hline & 150 & $5.6(2)$ & ${ }^{150} \mathrm{Sm},{ }^{134} \mathrm{BaO}$ & * & - & 34 & 4.9 & 25 & 4.1 & 19 & 3.8 & 18 & 3.7 & 43 & 5.6 \\
\hline \multirow[t]{7}{*}{$\mathrm{Sm}$} & 144 & $3.07(7)$ & ${ }^{144} \mathrm{Nd}$ & * & - & * & - & * & - & * & - & * & - & * & - \\
\hline & 147 & $14.99(18)$ & ${ }^{130} \mathrm{BaOH}$ & 0.0007 & 3.0 & 0.0007 & 3.0 & 0.14 & 3.0 & 0.18 & 3.0 & 0.016 & 3.0 & 0.005 & 3.0 \\
\hline & 148 & $11.24(10)$ & ${ }^{148} \mathrm{Nd},{ }^{132} \mathrm{BaO}$ & 51 & 6.5 & $*$ & - & $*$ & - & $*$ & - & $*$ & - & $*$ & - \\
\hline & 149 & $13.82(7)$ & ${ }^{132} \mathrm{BaOH}$ & 0.0003 & 3.0 & 0.0008 & 3.0 & 0.07 & 3.0 & 0.09 & 3.0 & 0.02 & 3.0 & 0.005 & 3.0 \\
\hline & 150 & 7.38 (1) & ${ }^{150} \mathrm{Nd},{ }^{134} \mathrm{BaO}$ & 76 & 9.6 & $*$ & - & $*$ & - & $*$ & - & $*$ & - & $*$ & - \\
\hline & 152 & $26.75(16)$ & $\begin{array}{l}{ }^{152} \mathrm{Gd},{ }^{136} \mathrm{CeO},{ }^{136} \mathrm{BaO} \text {, } \\
{ }^{135} \mathrm{BaOH}\end{array}$ & 0.8 & 3.0 & 0.9 & 3.0 & 9 & 3.3 & 11 & 3.4 & 2.4 & 3.1 & 1.7 & 3.1 \\
\hline & 154 & $22.75(29)$ & $\begin{array}{l}{ }^{154} \mathrm{Gd},{ }^{142} \mathrm{NdO},{ }^{138} \mathrm{CeO}, \\
{ }^{138} \mathrm{BaO},{ }^{137} \mathrm{BaOH}\end{array}$ & & 3.4 & 12 & 3.4 & 78 & 8.7 & 93 & 11 & 22 & 3.8 & 19 & 3.7 \\
\hline \multirow[t]{2}{*}{ Eu } & 151 & $47.81(3)$ & ${ }^{135} \mathrm{BaO},{ }^{134} \mathrm{BaOH}$ & 0.01 & 3.0 & 0.4 & 3.0 & 11 & 3.4 & 19 & 3.8 & 8.1 & 3.3 & 0.6 & 3.0 \\
\hline & 153 & $52.19(3)$ & ${ }^{137} \mathrm{BaO},{ }^{136} \mathrm{BaOH}$ & 0.03 & 3.0 & 0.7 & 3.0 & 19 & 3.7 & 34 & 4.6 & 14 & 3.5 & 1 & 3.0 \\
\hline \multirow[t]{7}{*}{$\mathrm{Gd}$} & 152 & $0.20(1)$ & $\begin{array}{l}{ }^{152} \mathrm{Sm},{ }^{136} \mathrm{CeO},{ }^{136} \mathrm{BaO}, \\
{ }^{135} \mathrm{BaOH}\end{array}$ & $*$ & - & $*$ & - & * & - & * & - & * & - & * & - \\
\hline & 154 & $2.18(3)$ & $\begin{array}{l}{ }^{154} \mathrm{Sm},{ }^{138} \mathrm{BaO},{ }^{137} \mathrm{BaOH}, \\
{ }^{142} \mathrm{NdO},{ }^{138} \mathrm{CeO}\end{array}$ & * & - & $*$ & - & $*$ & - & $*$ & - & * & - & * & - \\
\hline & 155 & $14.80(12)$ & ${ }^{138} \mathrm{BaOH},{ }^{139} \mathrm{LaO}$ & 11 & 3.4 & 24 & 4.1 & * & _- & * & _- & * & _- & 15 & 3.5 \\
\hline & 156 & $20.47(9)$ & ${ }^{156} \mathrm{Dy},{ }^{140} \mathrm{CeO}$ & 9.9 & 3.4 & 58 & 7.2 & * & - & * & - & * & - & 30 & 4.5 \\
\hline & 157 & $15.65(2)$ & ${ }^{141}$ PrO & 15 & 3.6 & 12 & 3.5 & 22 & 4.0 & 61 & 7.6 & 63 & 7.8 & 6.6 & 3.2 \\
\hline & 158 & $24.84(7)$ & ${ }^{158} \mathrm{Dy},{ }^{142} \mathrm{CeO},{ }^{142} \mathrm{NdO}$ & 3.8 & 3.1 & 15 & 3.5 & 29 & 4.2 & 67 & 7 & 71 & 7.3 & 9 & 3.3 \\
\hline & 160 & $21.86(19)$ & ${ }^{160} \mathrm{Dy},{ }^{1{ }^{14} \mathrm{SmO}},{ }^{144} \mathrm{NdO}$ & 14 & 3.5 & 21 & 3.8 & 24 & 4.0 & 37 & 4.8 & 43 & 5.4 & 20 & 3.8 \\
\hline $\mathrm{Tb}$ & 159 & 100 & ${ }^{143} \mathrm{NdO}$ & 0.3 & 3.0 & 4.8 & 3.2 & 12 & 3.4 & 29 & 4.4 & 36 & 5.1 & 3.1 & 3.1 \\
\hline \multirow[t]{7}{*}{ Dy } & 156 & $0.06(1)$ & ${ }^{156} \mathrm{Gd},{ }^{140} \mathrm{CeO}$ & $*$ & - & $*$ & - & $*$ & - & $*$ & - & $*$ & - & $*$ & - \\
\hline & 158 & $0.10(1)$ & ${ }^{158} \mathrm{Gd},{ }^{142} \mathrm{CeO},{ }^{142} \mathrm{NdO}$ & * & - & * & - & * & - & * & - & * & - & * & - \\
\hline & 160 & 2.34 (8) & ${ }^{160} \mathrm{Gd},{ }^{144} \mathrm{NdO},{ }^{144} \mathrm{SmO}$ & * & - & * & - & * & - & * & - & * & - & * & - \\
\hline & 161 & $18.91(24)$ & ${ }^{145} \mathrm{NdO}$ & 0.9 & 3.0 & 2.8 & 3.1 & 8 & 3.3 & 20 & 3.9 & 31 & 4.6 & 1.6 & 3.1 \\
\hline & 162 & $25.51(26)$ & ${ }^{162} \mathrm{Er},{ }^{146} \mathrm{NdO}$ & 2.4 & 3.1 & 4.9 & 3.2 & 13 & 3.5 & 31 & 4.6 & 49 & 6.2 & 3.2 & 3.1 \\
\hline & 163 & $24.90(16)$ & ${ }^{147} \mathrm{SmO}$ & 0.2 & 3.0 & 0.1 & 3.0 & 0.3 & 3.0 & 0.5 & 3.0 & 0.7 & 3.0 & 0.09 & 3.0 \\
\hline & 164 & $28.18(37)$ & ${ }^{164} \mathrm{Er},{ }^{148} \mathrm{SmO},{ }^{148} \mathrm{NdO}$ & 12 & 3.4 & 8.2 & 3.3 & 9.2 & 3.3 & 14 & 3.5 & 20 & 3.8 & 8.2 & 3.3 \\
\hline Но & 165 & 100 & ${ }^{149} \mathrm{SmO}$ & 0.03 & 3.0 & 0.1 & 3.0 & 0.06 & 3.0 & 0.6 & 3.0 & 0.9 & 3.0 & 0.09 & 3.0 \\
\hline $\mathrm{Er}$ & 162 & $0.14(1)$ & ${ }^{162} \mathrm{Dy},{ }_{1}^{146} \mathrm{NdO}$ & $*$ & - & $*$ & - & $*$ & - & $*$ & - & $*$ & - & $*$ & - \\
\hline & 164 & $1.61(3)$ & ${ }^{164} \mathrm{Dy},{ }^{1{ }^{14}} \mathrm{SmO},{ }^{148} \mathrm{NdO}$ & * & - & * & - & * & - & * & - & * & - & * & - \\
\hline & 166 & $33.61(35)$ & ${ }^{150} \mathrm{SmO},{ }^{150} \mathrm{NdO}$ & 0.4 & 3.0 & 1.8 & 3.1 & 7 & 3.2 & 20 & 3.9 & 25 & 4.1 & 1 & 3.0 \\
\hline & 167 & $22.93(17)$ & ${ }^{151} \mathrm{EuO}$ & 0.06 & 3.0 & 0.007 & 3.0 & 0.05 & 3.0 & 0.09 & 3.0 & 0.05 & 3.0 & 0.02 & 3.0 \\
\hline & 168 & $26.78(26)$ & ${ }^{168} \mathrm{Yb},{ }^{152} \mathrm{SmO},{ }^{152} \mathrm{GdO}$ & 0.7 & 3.0 & 0.8 & 3.0 & 1.4 & 3.0 & 2.6 & 3.1 & 2.8 & 3.1 & 0.7 & 3.0 \\
\hline & 170 & $14.93(27)$ & ${ }^{170} \mathrm{Yb},{ }^{154} \mathrm{GdO},{ }^{154} \mathrm{SmO}$ & 20 & 3.9 & 20 & 3.9 & 21 & 3.9 & 24 & 4.1 & 14 & 3.5 & 21 & 3.9 \\
\hline $\mathrm{Tm}$ & 169 & 100 & ${ }^{153} \mathrm{EuO}$ & 0.01 & 3.0 & 0.01 & 3.0 & 0.07 & 3.0 & 0.1 & 3.0 & 0.09 & 3.0 & 0.03 & 3.0 \\
\hline
\end{tabular}




$\begin{array}{ll}130 & 0.106(1) \\ 132 & 0.101(1) \\ 134 & 2.417(18) \\ 135 & 6.592(12) \\ 136 & 7.854(24) \\ 137 & 11.232(24) \\ 138 & 71.698(42) \\ 174 & 0.16(1) \\ 176 & 5.26(7) \\ 177 & 18.60(9) \\ 178 & 27.28(7) \\ 179 & 13.62(2) \\ 180 & 35.08(16)\end{array}$

Note: Bold isotopes are often used for quantitative determination of rare earth elements by several researchers. Bold and italic isotopes are more abundant isotopes proposed in this work for quantitative determination of rare earth elements. Bold interfering species are the major contributing species of spectroscopic interference over the particular isotope. *: Two to six orders of magnitude higher contribution as well as higher uncertainty; hence not suitable for analytical determinations. Column 3 in a and b contains at.\% of different isotopes and the parenthesis indicates the uncertainties on the last digits as per recommended by IUPAC in 1997.

a Synthetic mixture containing all rare earth elements in equal proportion of ppmw.

b Calculated assuming an error of $3 \%$ on each isotope signal determination and using the contributions of different interfering species. For atomic isobaric species, isotope abundances are used and for molecular isobaric species (oxide and hydroxide), the experimentally determined oxide and hydroxide yields by pneumatic nebuliser are used. 
interfering species and the measured uncertainty in those isotopes due to interference correction, in different samples with varying element composition, can decide the suitability of their choice for quantitative determination of rare earth elements. Using the recommended concentrations listed in Table 1, total contribution from different interfering species and the corresponding uncertainty were calculated for all the isotopes of various rare earth elements in a synthetic mixture of all rare earth elements in equal proportion as well as in different geological reference materials having different elemental compositions (AC-E, AGV-1, G-2, GSP-1). Similar calculation was also performed for chondrite normally used for obtaining chondrite-normalised curves. A measurement uncertainty of 3\% was assumed for the sake of calculation and comparison. The contribution and the corresponding uncertainties are listed in Table 2a. The selection of more than one isotope for different rare earth elements is discussed below.
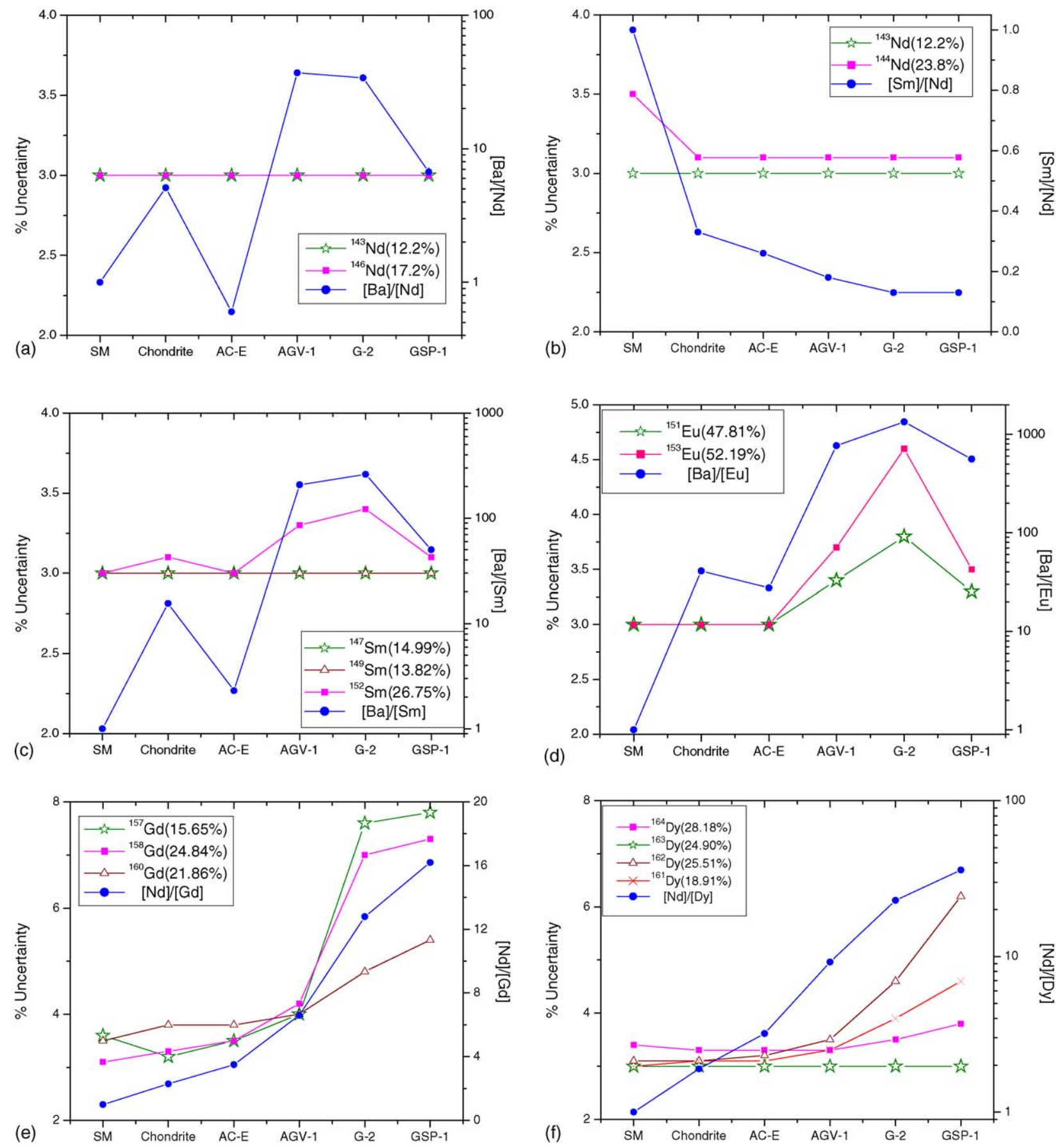

Fig. 2. Uncertainty propagation in the corrected rare earth elements in a synthetic mixture containing all rare earth elements in equal proportion and in different geological materials of different rare earth elements composition. 

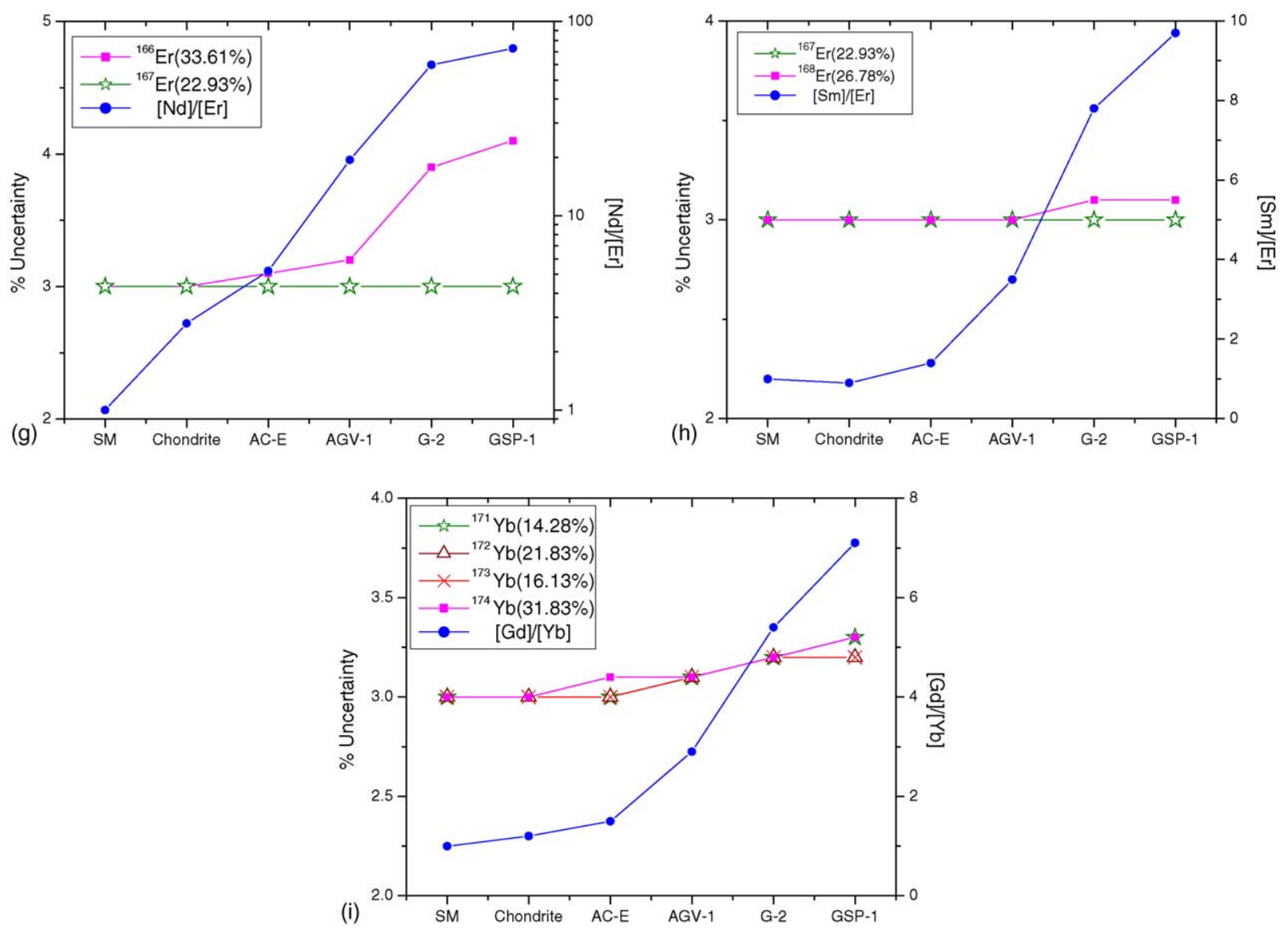

Fig. 2. (Continued).

\subsection{Selection of isotopes for determination of rare earth elements by ICP-QMS}

As mentioned in the introduction, a discussion on the choice of isotopes for determination of rare earths by ICPQMS was given by Longerich et al. [25]. However, the discussion given below justifies the use of more than one isotope for various rare earths considering the uncertainty involved due to the interference corrections.

\subsection{1. $N d$}

In many of the reports of rare earth elements determinations by ICP-QMS, ${ }^{143} \mathrm{Nd}\left(12.2\right.$ at.\%) or ${ }^{146} \mathrm{Nd}$ (17.2 at.\%) isotopes have been used for $\mathrm{Nd}$ determination $[3,6,12,25,29,30]$. As given in Table $2 \mathrm{a},{ }^{143} \mathrm{Nd}$ has no interference. However, ${ }^{146} \mathrm{Nd}$ has interference from ${ }^{130} \mathrm{BaO}$. Fig. $2 \mathrm{a}$ and $\mathrm{b}$ show the uncertainties in determination of different $\mathrm{Nd}$ isotopes in various samples (synthetic mixture (SM), chondrite and different rock samples normally used as reference materials). ${ }^{144} \mathrm{Sm}$ (3.07 at.\%) interferes with ${ }^{144} \mathrm{Nd}$ (23.8 at.\%) which is the isotope of $\mathrm{Nd}$ having the highest abundance. However, in most of the rock samples, concentration of Sm is less than that of $\mathrm{Nd}$ (Fig. 2b). Hence, ${ }^{144} \mathrm{Nd}$ can also be used with small correction for ${ }^{144} \mathrm{Sm}$ as given in Table 2a and as shown in Fig. 2b. Other Nd isotopes viz.
${ }^{142} \mathrm{Nd},{ }^{145} \mathrm{Nd},{ }^{148} \mathrm{Nd}$ and ${ }^{150} \mathrm{Nd}$ have either large interferences or small isotopic abundances and are, therefore, not recommended for Nd determination using ICP-QMS.

\subsection{2. $\mathrm{Sm}$}

In case of $\mathrm{Sm}$, there is no single isotope, which is interference free. Hence, ${ }^{147} \mathrm{Sm}(14.99$ at.\%) $[3,6,9,12,25,29,30]$ is the isotope used by different investigators for the determination of Sm by ICP-QMS due to extremely small contributions from ${ }^{130} \mathrm{BaOH}$. Fig. 2c shows the uncertainty in the determination of $\mathrm{Sm}$ in different samples with different $\mathrm{Ba} / \mathrm{Sm}$ concentration ratios. The highest abundant ${ }^{152} \mathrm{Sm}$ isotope $\left(26.75\right.$ at. $\%$ ) has interferences from ${ }^{152} \mathrm{Gd},{ }^{136} \mathrm{CeO}$ and oxide and hydroxide of $\mathrm{Ba}$. However, major contribution is from ${ }^{136} \mathrm{BaO}$ and ${ }^{135} \mathrm{BaOH}$. As seen in Fig. 2c, the uncertainty in determination of $\mathrm{Sm}$ increases from 3 to $3.5 \%$ in G-2 with $\mathrm{Ba} / \mathrm{Sm}$ concentration ratio $>200 .{ }^{152} \mathrm{Sm}$ with nearly double the at.\% abundance as those of ${ }^{147} \mathrm{Sm}$ and ${ }^{149} \mathrm{Sm}$ can also be used and would improve the detection sensitivity by a factor of 2 .

\subsubsection{Eu}

In case of $\mathrm{Eu}$, both the isotopes have almost the same natural abundance and are interfered by oxide and hydroxide of 
Table 3

Comparison of uncertainties $(\sigma)$ due to interference correction in the experimentally determined isotopes of rare earth elements in AGV-1 and G-2 using ICP-MS

\begin{tabular}{|c|c|c|c|c|c|c|c|}
\hline \multirow[t]{2}{*}{$\mathrm{RE}$} & \multirow[t]{2}{*}{ Isotope used } & \multicolumn{3}{|l|}{ AGV-1 } & \multicolumn{3}{|l|}{ G-2 } \\
\hline & & $\begin{array}{l}\text { Recommended } \\
\text { concentration }\end{array}$ & $\begin{array}{l}\text { Observed con- } \\
\text { centration }\end{array}$ & $\begin{array}{l}\text { Corrected concentra- } \\
\text { tion }( \pm \sigma)\end{array}$ & $\begin{array}{l}\text { Recommended } \\
\text { concentration }\end{array}$ & $\begin{array}{l}\text { Observed con- } \\
\text { centration }\end{array}$ & $\begin{array}{l}\text { Corrected concentra- } \\
\text { tion }( \pm \sigma)\end{array}$ \\
\hline $\mathrm{La}$ & 139 & $38 \pm 3$ & 39 & $39 \pm 1.2$ & $89 \pm 8$ & 93 & $93 \pm 2.7$ \\
\hline $\mathrm{Ce}$ & 140 & $67 \pm 5$ & 71 & $71 \pm 2.2$ & $160 \pm 10$ & 170 & $170 \pm 5.1$ \\
\hline $\operatorname{Pr}$ & 141 & $7.6 \pm 1.1$ & 8.6 & $8.6 \pm 0.0 .25$ & $18 \pm 2$ & 17.4 & $17.4 \pm 0.52$ \\
\hline \multirow[t]{4}{*}{$\mathrm{Nd}$} & 143 & $33 \pm 3$ & 31.4 & $31.4 \pm 0.9$ & $55 \pm 6$ & 54.7 & $54.7 \pm 1.7$ \\
\hline & 144 & & 33.5 & $32.8 \pm 1.4$ & & 57.9 & $56.9 \pm 2.4$ \\
\hline & 146 & & 31.8 & $31.8 \pm 1.3$ & & 54.7 & $54.7 \pm 2.3$ \\
\hline & & & Mean & $32.0 \pm 1.4^{\mathrm{a}}$ & & Mean & $55.4 \pm 2.5^{\mathrm{a}}$ \\
\hline \multirow[t]{4}{*}{$\mathrm{Sm}$} & 147 & $5.9 \pm 0.4$ & 6.2 & $6.2 \pm 0.25$ & $7.2 \pm 0.7$ & 7.7 & $7.7 \pm 0.30$ \\
\hline & 152 & & 6.6 & $6.1 \pm 0.15$ & & 8.5 & $7.8 \pm 0.18$ \\
\hline & 154 & & 9.9 & $6.0 \pm 0.24$ & & 13.1 & $7.4 \pm 0.40$ \\
\hline & & & Mean & $6.1 \pm 0.24^{\mathrm{a}}$ & & Mean & $7.6 \pm 0.37^{\mathrm{a}}$ \\
\hline \multirow{3}{*}{$\mathrm{Eu}$} & 151 & $1.6 \pm 0.1$ & 1.8 & $1.6 \pm 0.06$ & $1.4 \pm 0.1$ & 1.7 & $1.5 \pm 0.03$ \\
\hline & 153 & & 2.0 & $1.7 \pm 0.05$ & & 1.9 & $1.5 \pm 0.05$ \\
\hline & & & Mean & $1.7 \pm 0.09^{\mathrm{a}}$ & & Mean & $1.5 \pm 0.04^{\mathrm{a}}$ \\
\hline \multirow[t]{4}{*}{$\mathrm{Gd}$} & 157 & $5.0 \pm 0.5$ & 6.1 & $4.7 \pm 0.18$ & $4.3 \pm 0.8$ & 7.1 & $4.5 \pm 0.19$ \\
\hline & 160 & & 6.2 & $5.0 \pm 0.24$ & & 5.8 & $4.3 \pm 0.22$ \\
\hline & 158 & & 5.8 & $4.6 \pm 0.22$ & & 6.9 & $4.6 \pm 0.25$ \\
\hline & & & Mean & $4.8 \pm 0.30^{\mathrm{a}}$ & & Mean & $4.5 \pm 0.27^{\mathrm{a}}$ \\
\hline $\mathrm{Tb}$ & 159 & $0.7 \pm 0.1$ & 0.8 & $0.7 \pm 0.02$ & $0.48 \pm 0.08$ & 0.66 & $0.51 \pm 0.02$ \\
\hline \multirow[t]{5}{*}{ Dy } & 163 & $3.6 \pm 0.3$ & 3.7 & $3.7 \pm 0.11$ & $2.4 \pm 0.3$ & 2.4 & $2.4 \pm 0.09$ \\
\hline & 164 & & 4.2 & $4.0 \pm 0.17$ & & 2.9 & $2.5 \pm 0.11$ \\
\hline & 161 & & 3.9 & $3.6 \pm 0.13$ & & 3.0 & $2.4 \pm 0.07$ \\
\hline & 162 & & 4.1 & $3.6 \pm 0.14$ & & 3.3 & $2.4 \pm 0.08$ \\
\hline & & & Mean & $3.7 \pm 0.23^{\mathrm{a}}$ & & Mean & $2.4 \pm 0.10^{\mathrm{a}}$ \\
\hline Ho & 165 & $0.67 \pm 0.1$ & 0.68 & $0.68 \pm 0.02$ & $0.40 \pm 0.06$ & 0.39 & $0.38 \pm 0.01$ \\
\hline \multirow[t]{4}{*}{$\mathrm{Er}$} & 167 & $1.7 \pm 0.2$ & 1.9 & $1.9 \pm 0.07$ & $0.92 \pm 0.18$ & 0.93 & $0.92 \pm 0.03$ \\
\hline & 166 & & 2.0 & $1.9 \pm 0.03$ & & 1.13 & $0.89 \pm 0.04$ \\
\hline & 168 & & 1.9 & $1.9 \pm 0.07$ & & 0.92 & $0.88 \pm 0.05$ \\
\hline & & & Mean & $1.9 \pm 0.06^{\mathrm{a}}$ & & Mean & $0.90 \pm 0.05^{\mathrm{a}}$ \\
\hline $\mathrm{Tm}$ & 169 & $0.34 \pm 0.13^{*}$ & 0.27 & $0.27 \pm 0.01$ & $0.18 \pm 0.08^{*}$ & 0.12 & $0.12 \pm 0.005$ \\
\hline \multirow[t]{5}{*}{$\mathrm{Yb}$} & 171 & $1.72 \pm 0.19$ & 1.77 & $1.69 \pm 0.06$ & $0.80 \pm 0.17$ & 0.69 & $0.62 \pm 0.03$ \\
\hline & 174 & & 1.74 & $1.66 \pm 0.04$ & & 0.66 & $0.61 \pm 0.05$ \\
\hline & 172 & & 1.69 & $1.62 \pm 0.04$ & & 0.69 & $0.63 \pm 0.04$ \\
\hline & 173 & & 1.78 & $1.71 \pm 0.06$ & & 0.71 & $0.65 \pm 0.04$ \\
\hline & & & Mean & $1.67 \pm 0.06^{\mathrm{a}}$ & & Mean & $0.63 \pm 0.04^{\mathrm{a}}$ \\
\hline $\mathrm{Lu}$ & 175 & $0.27 \pm 0.03$ & 0.28 & $0.27 \pm 0.01$ & $0.11 \pm 0.02$ & 0.09 & $0.07 \pm 0.003$ \\
\hline
\end{tabular}

${ }^{\text {a }}$ Mean corrected concentrations show net uncertainty due to correction $\left(\sigma_{\text {total }}\right)$, obtained from $\sigma_{\text {external }}$ and $\sigma_{\text {internal }}$.

* Provisional value.

$\mathrm{Ba}$. However, the isotopes of $\mathrm{Ba}$ in the interfering oxide and hydroxide species over ${ }^{153}$ Eu have high abundances and give marginally higher correction and the corresponding uncertainty (Fig. 2d). Hence, ${ }^{151} \mathrm{Eu}$ is a better isotope compared to ${ }^{153} \mathrm{Eu}$ for Eu determination. However, both the Eu isotopes may be used for its determination without any significant difference in the results.

\subsection{4. $G d$}

In case of $\mathrm{Gd},{ }^{156} \mathrm{Gd}\left(20.47\right.$ at.\%), ${ }^{157} \mathrm{Gd}(15.65$ at.\%), ${ }^{158} \mathrm{Gd}\left(24.84\right.$ at. \%) and ${ }^{160} \mathrm{Gd}(21.86$ at. \%) are the high abundant isotopes. ${ }^{156} \mathrm{Gd}$ is interfered by ${ }^{140} \mathrm{CeO}$ seriously. In most of natural rock samples, Ce concentration is the highest amongst all the rare earth elements. Hence, ${ }^{156} \mathrm{Gd}$ cannot be used for analysis due to large interference, which leads to large uncertainty. ${ }^{157} \mathrm{Gd}$ is the most common choice for $\mathrm{Gd}$ $[3,6,9,25,30]$ and is interfered by ${ }^{141} \mathrm{PrO}$. However, the uncertainty in $\mathrm{Gd}$ determination using ${ }^{157} \mathrm{Gd}$ depends on the Pr con- centration in the sample and the error increases as $\mathrm{Pr} / \mathrm{Gd}$ concentration ratio increases (Table 2a, G-2 and GSP-1). ${ }^{158} \mathrm{Gd}$ has the highest natural abundance. But large corrections need to be applied due to high oxide yielding $\mathrm{Ce}$ and $\mathrm{Nd}$, which are normally present at higher concentrations than that of $\mathrm{Gd}$ in rock samples. As shown in Fig. 2e and Table $2 \mathrm{a},{ }^{160} \mathrm{Gd}$ is the best choice, since it has higher abundance than ${ }^{157} \mathrm{Gd}$ and the $\%$ uncertainty in the correction applied is less in different samples (Fig. 2e). Also ${ }^{138} \mathrm{Ba}^{19} \mathrm{~F}$ is another possible interference over ${ }^{157} \mathrm{Gd}$ and its degree of interference depends on the presence of $\mathrm{HF}$ or $\mathrm{F}$ in the sample. However, there is no practical way of monitoring $\mathrm{F}$ and HF. Hence, ${ }^{160} \mathrm{Gd}$ should be the best choice for Gd determination in unknown samples.

\subsection{5. $D y$}

${ }^{163} \mathrm{Dy}$ is generally used for its determination due to negligible contribution from ${ }^{147} \mathrm{SmO}[3,6,9,12,25,29,30]$. However, ${ }^{164}$ Dy can also be used, especially in those samples 
where $\mathrm{Nd} / \mathrm{Dy}$ concentration ratio is $<20$ as ${ }^{148} \mathrm{NdO}$ is the major interfering species and there is no significant difference in the uncertainty as shown in Fig. 2f. The other isotopes viz. ${ }^{161}$ Dy and ${ }^{162}$ Dy may also be used for verifying the concentration of Dy obtained using ${ }^{163}$ Dy and ${ }^{164}$ Dy isotopes.

\subsection{6. $\mathrm{Er}$}

In determination of Er by ICP-QMS, ${ }^{167} \mathrm{Er}$ is normally used due to very small interference from ${ }^{151} \mathrm{EuO}$ in its determination $[6,9,25,29]$. However, ${ }^{166} \mathrm{Er}$ having the highest natural abundance of $33.6 \%$ or ${ }^{168} \mathrm{Er}$ with $26.8 \%$ natural abundance can also be used along with the commonly used ${ }^{167} \mathrm{Er}$ (Fig. 2g and h).

\subsection{7. $Y b$}

For $\mathrm{Yb}$ determination, ${ }^{171} \mathrm{Yb}$ to ${ }^{174} \mathrm{Yb}$ isotopes have been used in different publications $[3,6,9,12,25,29,30]$. However, Table 2a shows almost the same contribution on all the four isotopes of $\mathrm{Yb}$ in all samples, as $\mathrm{GdO}$ is the common interfering species. Hence, highest abundant ${ }^{174} \mathrm{Yb}$ should be the best choice. Other than rare earth elements, $\mathrm{Hf}$ is another element, which gives interference at ${ }^{174} \mathrm{Yb}$. However, due to low abundance $(0.16 \%)$ of ${ }^{174} \mathrm{Hf}$ (Table $2 b$ ), its contribution over ${ }^{174} \mathrm{Yb}$ is not significant.

For other rare earth elements, the selection of isotope is straightforward. ${ }^{139} \mathrm{La},{ }^{140} \mathrm{Ce}$ and ${ }^{175} \mathrm{Lu}$ are the isotopes with high abundances and there is no interference in case of $\mathrm{La}$ and Ce and small interference over Lu from ${ }^{159} \mathrm{TbO} .{ }^{141} \mathrm{Pr},{ }^{159} \mathrm{Tm}$, ${ }^{165} \mathrm{Ho}$ and ${ }^{169} \mathrm{Tm}$ are the elements, which are mono-isotopic. Pr shows no interference and $\mathrm{Ho}$ and $\mathrm{Tm}$ show negligible interference contributions from $\mathrm{SmO}$ and $\mathrm{EuO}$, respectively. However, ${ }^{159} \mathrm{~Tb}$ shows major interference from ${ }^{143} \mathrm{NdO}$, and the contribution depends on the $\mathrm{Nd} / \mathrm{Tb}$ concentration ratio in sample. As the $\mathrm{Nd} / \mathrm{Tb}$ ratio increases from chondrite to GSP1 , the uncertainty in the corrected $\mathrm{Tb}$ concentration increases from 3 to $5 \%$.

\subsection{Experimental demonstration of uncertainty propagation due to interference correction in determination of rare earth elements in $A G V-1$ and $G-2$ using the proposed high abundant isotopes}

The use of different proposed isotopes of various rare earth elements has been demonstrated experimentally for the uncertainty propagation due to interference correction by analyzing two rock samples (AGV-1 and G-2) using ICP-QMS. The non-spectroscopic interferences that often arise due to matrix effect or due to instrumental fluctuations have been corrected using indium as an internal standard. ${ }^{115}$ In was used as an internal standard because of its high natural abundance. It shows isobaric interference with ${ }^{115} \mathrm{Sn}(0.34 \%)$ and ${ }^{99} \mathrm{RuO}$. Hence, both the rock samples (AGV-1 and G-2) were checked for $\mathrm{Sn}$ and $\mathrm{Ru}$. The concentration of Ru in both the samples is below the detection limits. Due to low natural abundance of ${ }^{115} \mathrm{Sn}$, its contribution to internal standard $\left({ }^{115} \mathrm{In}\right)$ signal was $<0.1 \%$ and hence was neglected.
Table 3 shows the results of determination of rare earth elements in AGV-1 and G-2 using the commonly used as well as other proposed isotopes by ICP-QMS and their comparison on basis of uncertainty due to interference corrections. The measured intensities of the isotopes used in the calculations were blank subtracted and the net uncertainty obtained from the standard deviations of gross intensity and blank was used for determining the propagation uncertainty due to correction methodology. The R.S.D.\% on the intensity values used for correction would lead unnecessarily larger errors than using R.S.D.\% on ratios in cases when isotope ratios are measured with high precision using multi-collector detector system. However, the difference between the two approaches is marginal in the present case, since both the isotope ratios as well as intensity values have comparable uncertainties in view of the single detector used. The isotopes for each element are placed in the order of preference of their usage for particular rare earth element determination. As an example, in case of $\mathrm{Nd},{ }^{143} \mathrm{Nd}(12.2$ at.\%) having no isobaric interference is quite often used for its determination by different researchers. The proposed ${ }^{144} \mathrm{Nd}$ isotope in this work having almost double natural abundance (23.8 at. \%) compared to ${ }^{143} \mathrm{Nd}$ shows isobaric interference from ${ }^{144} \mathrm{Sm}$. After applying the interference correction for ${ }^{144} \mathrm{Sm}$, the uncertainty was found to be $4 \%$ in $\mathrm{Nd}$ determination using ${ }^{144} \mathrm{Nd}$ compared $3 \%$ using ${ }^{143} \mathrm{Nd}$ in both the rock samples (AGV-1 and G-2). Similarly in case of Sm, ${ }^{147} \mathrm{Sm}$ (14.99 at.\%) is the commonly used isotope for $\mathrm{Sm}$ determination by different researchers, due to negligible interference from ${ }^{130} \mathrm{BaOH}$. The proposed isotope ${ }^{152} \mathrm{Sm}$ having almost double the natural abundance (26.75 at.\%) compared to that of ${ }^{147} \mathrm{Sm}$ shows interferences from ${ }^{136} \mathrm{BaO}$ and ${ }^{135} \mathrm{BaOH}$. After accounting for the interferences, the uncertainty due to correction in the determination of $\mathrm{Sm}$ concentration using ${ }^{152} \mathrm{Sm}$ should be more than that using ${ }^{147} \mathrm{Sm}$ in AGV-1 and in G-2 rock samples (Table 2a). However, experimentally it was found that the uncertainty due to correction in the determination of Sm concentration using ${ }^{152} \mathrm{Sm}$ is lesser (3\% in AGV-1 and $2 \%$ in G-2) than that using ${ }^{147} \mathrm{Sm}$ (4\% in both AGV-1 and G-2) (Table 3). This is due to the more précised measurement of high abundant isotope $\left({ }^{152} \mathrm{Sm}\right)$ of $\mathrm{Sm}$ than the low abundant one $\left({ }^{147} \mathrm{Sm}\right)$. ${ }^{154} \mathrm{Sm}$ is another high abundant isotope which was used for quantification. However, due to large corrections for ${ }^{138} \mathrm{BaO}$ and ${ }^{137} \mathrm{BaOH}$, the uncertainty in the corrected concentration of Sm using this isotope is more than that obtained by using the other isotopes. In case of $\mathrm{Gd},{ }^{160} \mathrm{Gd}$ isotope should be preferred compared to routinely used ${ }^{157} \mathrm{Gd}$, especially for G-2 or other samples where $\mathrm{Pr} / \mathrm{Gd}$ amount ratio is likely to be higher. For other rare earth elements, having multiple choices of isotopes for quantification, the uncertainties due to interference corrections in the corrected concentrations are found to be practically same. Hence, high abundant isotopes amongst them are preferable for quantification. One should note that the corrected concentrations using those high abundant but relatively more interfered isotopes show comparable uncertainties. Hence, it is advisable to use 
these isotopes also in quantification in order to improve the sensitivity.

Since, ICP-MS is a multi-elemental determination technique, the determination of more than one element along with their different isotopes is possible at a time. Also the time required for multiple isotopes determination is not significantly large. Using Microsoft Excel worksheet, correction methodology can be easily applied. With the speed and ease of application of correction methods without any additional experimental effort, the enhanced sensitivity using high abundant isotope is an added advantage, since, the uncertainty due to the corrections in most of the high abundant and the commonly used isotopes is practically same.

\section{Conclusion}

The propagation of measurement uncertainties through the correction methodology has been studied for different isotopes of rare earth elements in the range of $m / z$ 130-176. It has been shown that the uncertainty propagation through the correction methodology increases with the increase in contribution from interfering species. At the same time, assuming the same total contribution, the uncertainty decreases with the number of contributing species. The estimation of degree of interference and the corresponding uncertainty after its correction facilitates the choice for high abundant isotopes in determination of rare earth elements using ICP-QMS. The proposed isotopes have been tested experimentally in two geological samples (AGV-1 and G-2), which are commonly used as reference standards for rare earth elements determination by ICP-QMS. The comparable uncertainties due to interference correction are obtained in the corrected concentrations, by the commonly used and proposed isotopes. This proved the suitability of high abundant isotopes for sensitive detection, for some of the rare earth elements.

\section{Acknowledgements}

This work is financially supported by National Science Council, Republic of China under contract no. NSC 90-2113M-002-036. N. M. R. is thankful to Institute of Atomic and Molecular Sciences, Academia Sinica, for providing fellowship and research facilities during the collaboration.

\section{References}

[1] L. Liang, P.C. D'Haese, L.V. Lamberts, F.L. van de Vyver, E. De Broe, Determination of gadolinium in biological material using graphite furnace atomic absorption spectrometry with a tantalum boat after solvent extraction, Anal. Chem. 63 (1991) 423-427.

[2] T. Prohaska, S. Hann, C. Latkoczy, G. Stingeder, Determination of rare earth elements, $U$ and $T h$ in environmental samples by inductively coupled plasma double focusing sector field mass spectrometry, J. Anal. At. Spectrom. 14 (1999) 1-8.
[3] K. Inagaki, H. Haraguchi, Determination of rare earth elements in human blood serum by inductively coupled plasma mass spectrometry after chelating resin pre-concentration, Analyst 125 (2000) 191-196.

[4] A. Montaser, D.W. Golightly, Inductively Coupled Plasma in Analytical Atomic Spectrometry, 2nd ed., VCH, New York, 1992.

[5] F.E. Lichte, A.L. Meier, J.G. Crock, Determination of rare earth elements in geological material by inductively coupled plasma mass spectrometry, Anal. Chem. 59 (1987) 1150-1157.

[6] K.E. Jarvis, Determination of rare earth elements in geological samples by inductively coupled plasma mass spectrometry, J. Anal. At. Spectrom. 4 (1989) 563-570.

[7] P. Dulski, Interference of oxide, hydroxide and chloride analyte species in the determination of rare earth elements in geological samples by inductively coupled plasma mass spectrometry, Fresen. Z. Anal. Chem. 350 (1994) 194-207.

[8] C. Pin, P. Telouk, J.L. Imbert, Direct determination of Sm:Nd ratio in geological material by inductively coupled plasma quadrupole mass spectrometry with cryogenic desolvation. Comparison with isotope dilution thermal ionization mass spectrometry, J. Anal. At. Spectrom. 10 (1995) 93-98.

[9] X.P. Yan, R. Kerrich, M.J. Hendry, Flow injection on-line group pre-concentration and separation of ultra-trace rare earth elements in environmental and geological samples by precipitation using knotted reactor as a filter less collector for inductively coupled plasma mass spectrometric determination, J. Anal. At. Spectrom. 14 (1999) 215-221.

[10] W. Diegor, H. Longerich, T. Abrajano, I. Horn, Applicability of high-pressure digestion technique to the analysis of sediment and soil samples by inductively coupled plasma mass spectrometry, Anal. Chim. Acta 431 (2001) 195-207.

[11] N.M. Raut, L.S. Huang, S.K. Aggarwal, K.C. Lin, Determination of lanthanides in rock samples by inductively coupled plasma mass spectrometry using thorium as oxide and hydroxide correction standard, Spectrochim. Acta - Part B 58 (2003) 809-822.

[12] L. Halicz, I. Segal, O. Yoffe, Direct rare earth elements determination in fresh water using ultrasonic nebulization ICP-MS, J. Anal. At. Spectrom. 14 (1999) 1579-1581.

[13] H. Tao, A. Miyazaki, Decrease of solvent water loading in inductively coupled plasma mass spectrometry by using a membrane separator, J. Anal. At. Spectrom. 10 (1995) 1-5.

[14] J.W.H. Lam, G. Horlick, A comparison of Ar and mixed gas plasmas for inductively coupled plasma mass spectrometry, Spectrochim. Acta - Part B 45 (1990) 1313-1325.

[15] H. Louie, S.Y.P. Soo, Use of nitrogen and hydrogen in inductively coupled plasma mass spectrometry, J. Anal. At. Spectrom. 7 (1992) 557-564.

[16] M.A. Vaughan, G. Horlick, Effect of sampler and skimmer orifice size on analyte and analyte oxide signals in inductively coupled plasma mass spectrometry, Spectrochim. Acta - Part B 45 (1990) 1289-1299.

[17] J.W.H. Lam, G. Horlick, Effect of sampler-skimmer separation in inductively coupled plasma mass spectrometry, Spectrochim. Acta Part B 45 (1990) 1327-1338.

[18] M. Iglesias, N. Gilcon, E. Poussel, J.M. Mermet, Evaluation of an ICP-collision/reaction cell-MS system for the sensitive determination of spectrally interfered and non-interfered elements using the same gas conditions, J. Anal. At. Spectrom. 17 (2002) 1240-1247.

[19] H. Louie, M. Wu, P. Di, P. Snitch, G. Chapple, Direct determination of trace elements in sea water using reaction cell inductively coupled plasma mass spectrometry, J. Anal. At. Spectrom. 17 (2002) 587-591.

[20] J.R. Bacon, A.M. Ure, The correction of interferences effect in the determination of the rare earth elements and $\mathrm{Hf}$ by spark source mass spectrometry, Anal. Chim. Acta 105 (1979) 163-176.

[21] E.H. Van Veen, S. Bosch, M.T.C. De Loos-Vollebregt, Spectral interpretation and inteference correction in inductively coupled 
plasma mass spectrometry, Spectrochim. Acta - Part B 49 (1994) $1347-1361$.

[22] M.A. Vaughan, G. Horlick, Correction procedures for rare earth element analysis in inductively coupled plasma mass spectrometry, Appl. Spectrosc. 44 (1990) 587-593.

[23] K.E. Jarvis, A.L. Gray, E. McCurdy, Avoidance of spectral interference on Eu in inductively coupled plasma mass spectrometry by sensitive measurement of double charged ions, J. Anal. At. Spectrom. 4 (1989) 743-747.

[24] X. Cao, M. Yin, X. Wang, Elimination of spectral interference from polyatomic ions with rare earth elements in inductively coupled plasma mass spectrometry by combining algebraic correction with chromatographic separation, Spectrochim. Acta - Part B 56 (2001) 431-441.

[25] H.P. Longerich, B.J. Fryer, D.F. Strong, C.J. Kantipuly, Effects of operating conditions on the determination of the rare earth elements by inductively coupled plasma mass spectrometry (ICP-MS), Spectrochim. Acta - Part B 42 (1987) 75-92.

[26] S.H. Ke, L.S. Huang, J.S. Huang, K.C. Lin, Flow injection inductively coupled plasma mass spectrometer with an ultrasonic nebuliser membrane dryer: application to trace lead detection in aqueous solution and in sea water, Appl. Spectrosc. 55 (2001) 604-610.
[27] K. Ashley, R.N. Andrews, L. Cavazos, M. Demange, Ultrasonic extraction as a sample preparation technique for elemental analysis by atomic spectrometry, J. Anal. At. Spectrom. 16 (2001) 1147-1153.

[28] D.J. Douglas, J.B. French, An improved interface for inductively coupled plasma mass spectrometry, Spectrochim. Acta - Part B 41 (1986) 197-204.

[29] Y. Hu, F. Vanhaecke, L. Moens, R. Dams, P. del Castilho, J. Japenga, Determination of aqua-regia soluble content of rare earth elements in fertilizer, animal fodder, phosphate and manure samples using inductively coupled plasma mass spectrometry, Anal. Chim. Acta 373 (1998) 95-105.

[30] L. Haichen, L. Ying, Z. Zhanxia, Determination of ultra-trace rare earth elements in chondritic meteorites by inductively coupled plasma mass spectrometry, Spectrochim. Acta - Part B 53 (1997) $1399-1404$

[31] K. Govindaraju, Compilation report on Ailsa Craig granite ACE with the participation of 128 GIT-IWG laboratories, Geostand. Newslett. 11 (1987) 203-255.

[32] K. Govindaraju, Compilation of working values and sample description for 272 geostandards, Geostand. Newslett. 13 (1989) 1-113.

[33] E. Anders, N. Grevesse, Abundances of elements: meteoritic and solar, Geochim. Cosmochim. Acta 53 (1989) 197-214. 